Polymer Journal, Vol. 6, No. 2, pp 85-93 (1974)

\title{
Molecular Motion in Crystalline Lysozyme
}

\author{
Toshiharu TAKIzAWA \\ Department of Physics, Faculty of General Study, \\ Gunma University, Maebashi, Japan. \\ Yasuhiro MiYoshi \\ Department of Botany, Faculty of Science, \\ University of Tokyo, Tokyo, Japan. \\ Nobuhiko SAITô \\ Department of Applied Physics, Waseda University, \\ Tokyo, Japan.
}

(Received February, 3, 1973)

\begin{abstract}
Broad-line proton magnetic resonance (PMR) and differential thermal analysis (DTA) were employed to investigate the molecular motion of crystalline lysozyme. The motional narrowing of the broad component of PMR and the endothermal peak in DTA were observed at almost the same temperature. This temperature changed reversibly from about 70 to $200^{\circ} \mathrm{C}$ depending upon the water content of the sample. The PMR line-narrowing and the endothermal peaks are thought to be due to the conformational changes of the protein caused by the melting of the crystals. By applying Flory's theory of the melting point depression, it was shown that the interaction energy between water and lysozyme molecule became larger in a region where the water content was below $15 \mathrm{wt} \%$. Furthermore, PMR line-narrowing of narrow component was observed in the temperature range from 20 to $50^{\circ} \mathrm{C}$. The corresponding small endothermal peak was also observed in DTA.

KEY WORDS Crystalline Lysozyme / Molecular Motion / Proton Magnetic Resonance / Differential Thermal Analysis / Thermogravimetric Analysis / Melting Slant Line Denaturation / Structural Stability /
\end{abstract}

There have been a number of studies of lysozyme in solutions by spectrophotometry and proton-magnetic-resonance spectroscopy. ${ }^{1-6}$ Structural information derived from these studies suggests that the structure of the enzyme in solution (as determined by Phillips and his collaborators ${ }^{7}$ ) is similar to that in the crystalline state. A detailed static picture of the enzyme reaction has been built up by determination of the structures of the enzyme-substrate and the enzyme-inhibitor complexes. ${ }^{8-9}$ The kinetics of the enzymatic reaction has also been studied by many workers. ${ }^{10-15}$ It is interesting to explain the kinetics of the enzymatic reactions of lysozyme on the basis of this structural information. The fact that a remarkable temperature dependence is observed in this enzymatic reaction suggests that molecular motion plays a very important role in this problem. An attempt was therefore made first to investigate molecular motion in crystalline lysozyme over a temperature range where the rate of enzymatic reaction shows a maximum.

In this paper, some experimental results are described on the molecular motion of crystalline lysozyme as studied by broad-line proton magnetic resonance (PMR) and differential thermal analysis (DTA).

\section{EXPERIMENTAL}

\section{Materials}

Six-times recrystallized egg-white lysozyme was supplied by Seikagaku Kogyo Co., Ltd. For the measurement of PMR, deuterium replacement of exchangeable protons in the lyso- 


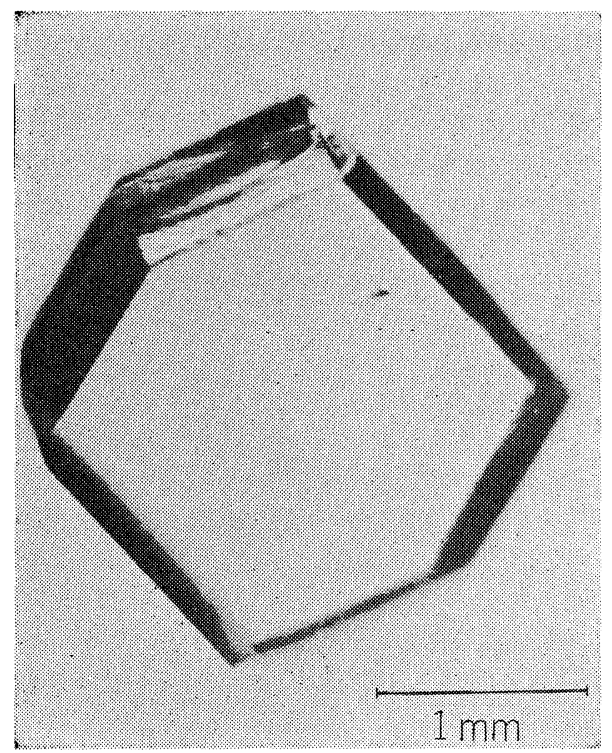

Figure 1. Microscopic photograph of a single crystal of lysozyme.

zyme was accomplished by dialyzing $20-\mathrm{m} l$ lysozyme solution in $\mathrm{D}_{2} \mathrm{O}$ against $100 \mathrm{ml}$ of $\mathrm{D}_{2} \mathrm{O}$ (purity 99.8\%) for approximately $24 \mathrm{hr}$, and then lyophilizing once or twice. This procedure was found to give good exchange with virtually no denaturation precipitate. For the crystallization of the lysozyme, $2.5-\mathrm{mmol} \mathrm{D}_{2} \mathrm{O}$ solution of deuterized lysozyme was prepared. The $\mathrm{pD}$ was adjusted at 4.2 with deuterochloride and 0.5 -mol sodium chloride. Twenty millilitre of the solution was kept in a test tube for 7 days at $4^{\circ} \mathrm{C}$, after having been subjected to a temperature that decreased from 25 to $4^{\circ} \mathrm{C}$ at a rate of $1^{\circ} \mathrm{C} / \mathrm{hr}$. A single crystal obtained by this treatment had a size of about $2 \times 2 \times 1\left(\mathrm{~mm}^{3}\right)$ (Figure 1).

For the preparation of noncrystalline but undenatured samples, which are referred to as amorphous samples in this paper, the same $\mathrm{D}_{2} \mathrm{O}$ solution used for the crystallization was lyophilized rapidly at the temperature of liquid nitrogen. X-ray diffraction of these samples showed only an amorphous halo. Denatured samples were also prepared by lyophilizing the $\mathrm{D}_{2} \mathrm{O}$ solution rapidly at the temperature of liquid nitrogen after boiling it at $90^{\circ} \mathrm{C}$ for about $2 \mathrm{hr}$.

Further, as it has been known that the enzyme-substrate complex is more stable to heat than the enzyme alone in the solution, ${ }^{16}$ the preliminary studies on molecular motion were carried out for the complex. $N$-acetyl-D-glucosamine purchased from Seikagaku Kogyo Co., Ltd. was used without further purification. Twenty five millimole of $N$-acetyl-D-glucosamine was added to $20 \mathrm{~m} l$ of $2.5-\mathrm{mmol}$ lysozyme solution. The mixed solution was lyophilized after stirring for $2 \mathrm{hr}$ at room temperature. This sample was used as the complex.

Preparation of the samples for measurement of DTA was also carried out in the same way as mentioned above, but $\mathrm{H}_{2} \mathrm{O}$ was used as the solvent instead of $\mathrm{D}_{2} \mathrm{O}$. Dry samples were obtained by drying at $60^{\circ} \mathrm{C}$ and in vacuo below $10^{-3}$ Torr for $24 \mathrm{hr}$. The amount of water $\left(\mathrm{H}_{2} \mathrm{O}\right.$ or $\mathrm{D}_{2} \mathrm{O}$ ) in the samples was controlled by placing the samples in various atmospheres having differing vapor pressures for about $20 \mathrm{hr}$.

\section{Apparatus}

$P M R$. Broad-line proton-magnetic-resonance spectra were obtained on a spectrometer type 350 of JEOL. Co., Ltd. and on a Varian Associates spectrometer type DP 60 . For measurements of temperature dependence, the samples were heated or cooled at a rate of $5^{\circ} \mathrm{C} / \mathrm{hr}$ and were kept at each measuring temperature for about $30 \mathrm{~min}$ before the measurement. These treatments induced thermal equilibrium in the samples. Temperatures were regulated within $0.5^{\circ} \mathrm{C}$.

$D T A$. A sample holder and a furnace assembly used in this work were constructed so as to enable the analysis of samples within the range 1 to $200 \mathrm{mg}$. A cylindrical aluminium cell (microcell), $2 \mathrm{~mm}$ in diameter and $2 \mathrm{~mm}$ in depth, was used to analyze samples ranging from 1 to $20 \mathrm{mg}$ (microDTA), and a silica cell (macrocell) was used for the analysis of 20 to $200 \mathrm{mg}$ of the sample (macroDTA). The heating rate of the furnace was controlled by a solid state temperature programmer (AGNE HPC-1500). Most measurements were carried out at a rate of $5^{\circ} \mathrm{C} / \mathrm{min}$. To analyze thermal behavior in the airtight state, the cell was covered with a thin aluminium plate and sealed with epoxy resin.

For simultaneous measurements of macroDTA and thermogravimetric analysis (TGA), a Rigaku- 
denki differential thermobalance was used. The differential scanning calorimetry (DSC) was also carried out by using the AGNE DSC-1500 to analyze precisely thermal behavior in the region below the denaturation temperature.

\section{RESULTS}

\section{$P M R$}

Derivative spectra of the broad-line PMR of the dry crystalline lysozyme are shown in Figure 2. These spectra consist of narrow and broad components, which can be treated approximately as the absorption of Lorentzian and Gaussian types, respectively. As is well known, the absorption of the Lorentzian type originates from proton systems moving with correlation times shorter than the inverse square root of the adiabatic second moment of an absorption spectrum represented in sec unit, and the Gaussian type from those with longer correlation times. ${ }^{17}$ As such, it may be reasonable to consider that there are at least two different proton groups with regard to motional freedom in this crystalline sample.

The temperature dependence of the maximum slope width of each component of the absorption spectra is shown in Figure 3 for both dry and wet (water content, about $35 \%$ by wt $\%$ ) crystalline sample. In this figure the broad and the narrow components of the dry sample are expressed by the open and closed circles, respectively, while the broad component of the wet sample is expressed by open triangles. An

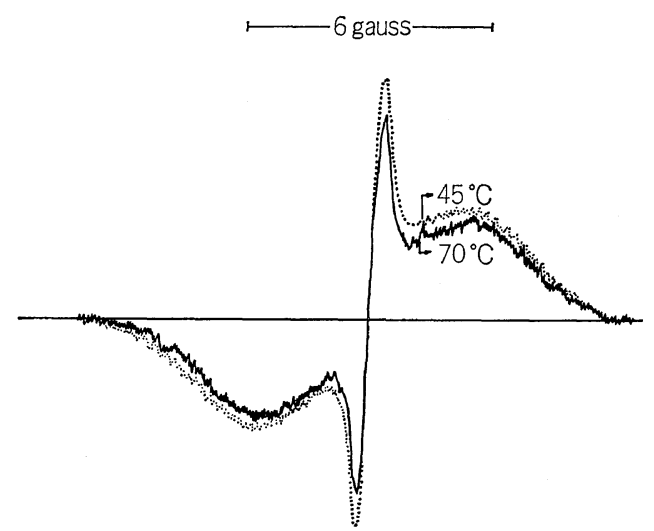

Figure 2. Derivative spectra of the broad-line PMR of the dry crystalline lysozyme.

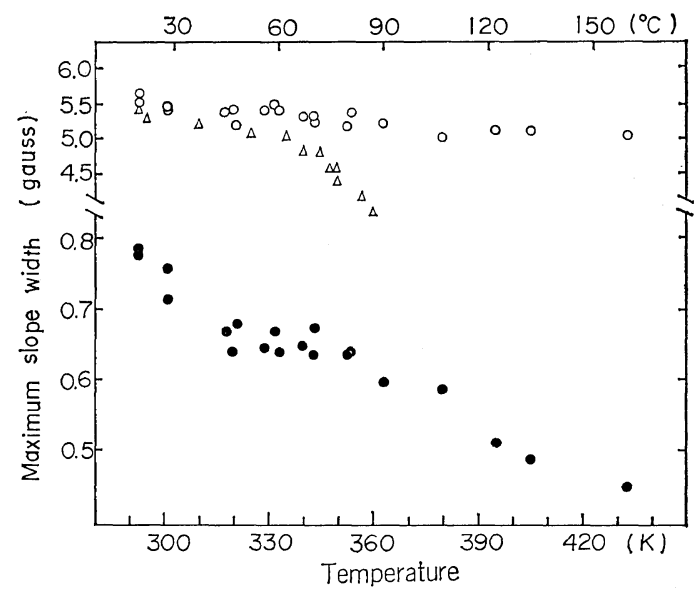

Figure 3. The temperature dependence of maximum slope widths of the broad and the narrow components in the absorption spectra: $\bigcirc$, broad component for the dry crystalline lysozyme; narrow component for the dry crystalline lysozyme; $\triangle$, broad component for the wet crystalline lysozyme.

appreciable change of line-width with temperature did not appear in the range from 20 to $160^{\circ} \mathrm{C}$ for the broad component of the dry samples. However, a definite change could be recognized in the range from 20 to $50^{\circ} \mathrm{C}$ for the narrow component.

For the wet samples, the narrowing of the broad component appeared in the vicinity of $100^{\circ} \mathrm{C}$. It was found that the narrowing temperature depends markedly on the amount of the absorbed water, that is, the smaller the amount of absorbed water, the higher the narrowing temperature. This result was similar to the result observed by Iwayanagi and Sugiura. ${ }^{18}$

The temperature dependence of the ratio of the integrated intensity of absorption of the broad component to that of the total is shown in Figure 4 for both the dry crystalline and the dry amorphous samples. The open and the closed circles in this figure express the values for the crystalline and the amorphous samples, respectively. As shown in this figure, the ratio was the same for both the dry samples, and did not change over the temperature range from 20 to $160^{\circ} \mathrm{C}$. From these results, it may be considered that the narrow component is not produced by the noncrystalline parts of the 


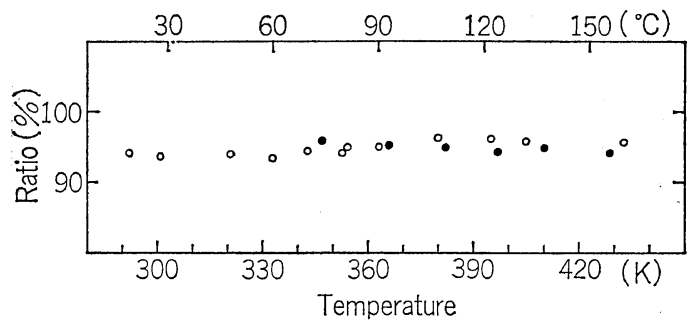

Figure 4. The temperature dependence of the ratio of the integrated intensity of absorption of the broad component to that of the total: $\bigcirc$, dry crystalline lysozyme; $\mathbf{0}$, dry amorphous lysozyme.

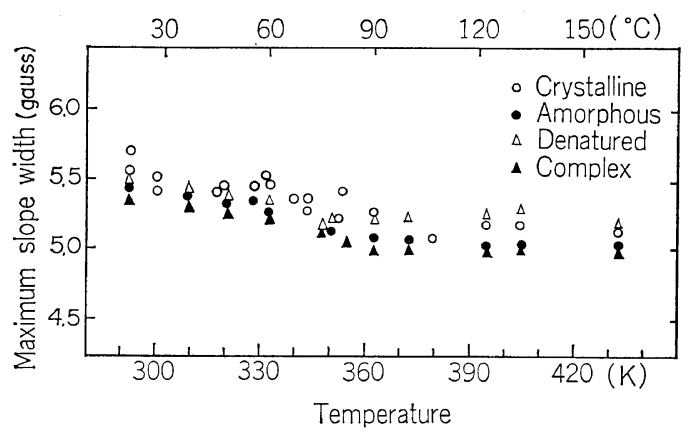

Figure 5. Temperature dependences of the maximum slope width of a broad component of various dry samples.

samples and the transition of protons from the state contributing to broad component to that of the narrow component (and vice versa) does not occur at these temperatures for both these samples.

Temperature dependences of the maximum slope width of a broad component are shown in Figure 5 for various dry samples. Though the elevation of the thermal stability was expected for the complex, no remarkable difference was observed between the complex and the other samples. This result shows that in the dry state the substrate has no distinct effect on the molecular motion of the enzyme at these temperatures. $D T A$

The results of the simultaneous measurements of microDTA and TGA are shown in Figure 6 for crystalline lysozyme treated under a condition of $4{ }^{\circ} \mathrm{C}, 70-\%$ relative humidity ( $\left.\mathrm{RH}\right)$. The macro- and microDTA curves were characterized by two endothermal peaks, a broad

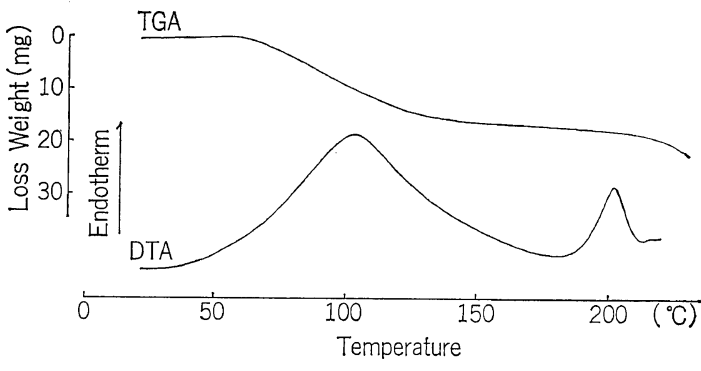

Figure 6. MacroDTA and TGA curves of crystalline lysozyme dried at a low temperature: Rate, $5^{\circ} \mathrm{C} / \mathrm{min}$; sample weight, $170 \mathrm{mg}$.

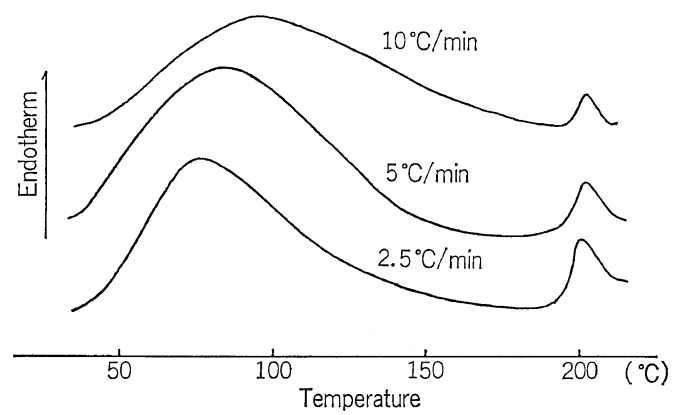

Figure 7. Effect of heating rate on microDTA curves of crystalline lysozyme dried at low temperature: Sample weight, $9 \mathrm{mg}$.

Table I. Effect of sample weight ${ }^{\mathrm{a}}$

\begin{tabular}{crrrrrr}
\hline \multirow{2}{*}{ Weight, mg } & \multicolumn{3}{c}{ Microcell } & & \multicolumn{2}{c}{ Macrocell } \\
\cline { 2 - 3 } & 2.1 & 4.4 & 9.2 & & 41 & 170 \\
\hline Peak temperature & & & & & \\
$T_{\mathrm{a}},{ }^{\circ} \mathrm{C}$ & 58 & 66 & 80 & & 90 & 100 \\
$T_{\mathrm{b}},{ }^{\circ} \mathrm{C}$ & 202 & 202 & 202 & & 202 & 202 \\
\hline
\end{tabular}

a Sample, crystal dried at low temperature.

peak near $100^{\circ} \mathrm{C}\left(T_{\mathrm{a}}\right)$ and a sharp peak at $202^{\circ} \mathrm{C}$ $\left(T_{\mathrm{b}}\right)$.

When the sample weight was increased, $T_{\mathrm{a}}$ in micro- and macroDTA curves shifted to higher temperatures, whereas $T_{\mathrm{b}}$ was kept unchanged as shown in Table I.

Further $T_{\mathrm{a}}$ was also affected by changes in heating rate. In Figure 7, this result is shown on microDTA curves for crystalline lysozyme treated at $4{ }^{\circ} \mathrm{C}$ and $70-\% \mathrm{RH}$.

A broad endothermal peak near $100^{\circ} \mathrm{C}$ in macroDTA has been observed in many bio- 
polymers, and has been identified as water evaporation from the samples. ${ }^{19,20}$ In our experiment, $T_{\mathrm{a}}$ could also be explained by water evaporation, since the appearance of $T_{\mathrm{a}}$ was accompanied by the weight loss in TGA (see Figure 6) and when water evaporation was suppressed by the closed cell this broad peak did not appear. The dependence of $T_{\mathrm{a}}$ on sample weight and heating rate as shown in Figure 7 and Table $I$ is well explained by water evaporation, because these shifts in $T_{\mathrm{a}}$ agree with the generally observed tendencies in DTA of the wet samples, in which the water evaporation occurs at higher temperatures, when the heating rate or sample weight is larger.

When the sample contained a lot of water or the packing of the samples was so tight that desorption of water was prevented, this broad peak seemed to have a shoulder towards lower temperature regions. To see whether or not this shoulder originates from water evaporation as well as $T_{\mathrm{a}}$, differential thermal analysis was carried out by using a closed microcell to suppress water evaporation. A sharp endothermal peak $\left(T_{\mathrm{c}}\right)$ was observed at the temperature where the shoulder had appeared in an open microcell (shown in Figure 8), and this peak was largely affected by the water content of the samples, but only slightly affected by the heating rate or the sample weight contrary to $T_{\mathrm{a}}$ (see Table II). Therefore, it will be reasonable to assume that this sharp endothermal peak $\left(T_{\mathrm{c}}\right)$ is caused by a source other than water evaporation. The slight increase of $T_{\mathrm{e}}$ with decrease of sample weight is shown in Table II by the example of the sample containing about $12 \mathrm{wt} \%$ of water. This result was explained by the reason that the smaller the sample weight, the more dry

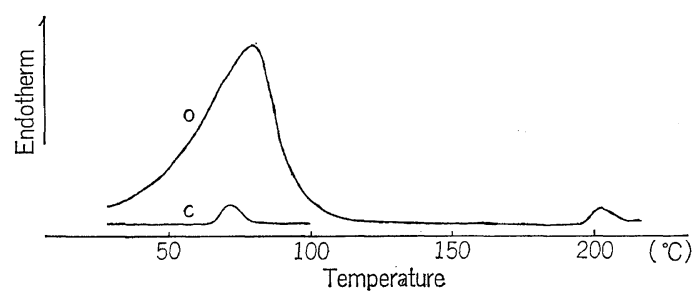

Figure 8. MicroDTA curves of wet lysozyme crystals, by using open cell (O), closed cell (C): Rate, $5^{\circ} \mathrm{C} / \mathrm{min}$; sample weight, $10 \mathrm{mg}$.
Table II. Effect of sample weight on the endothermal peak temperatures $\left(T_{\mathrm{c}}\right)$ observed by using a closed microcell ${ }^{\mathrm{a}}$

\begin{tabular}{ccccc}
\hline Sample weight, mg & 0.9 & 1.5 & 2.7 & 5.8 \\
\hline$T_{\mathrm{c}},\left({ }^{\circ} \mathrm{C}\right)$ & 107 & 100 & 99 & 98 \\
\hline
\end{tabular}

a Heating rate, $5^{\circ} \mathrm{C} / \mathrm{min}$; sample, water contents of about 12 wt $\%$.

Table III. Endothermal peak temperature $\left(T_{\mathrm{c}}\right)$ in closed microDTA of various samples ${ }^{a}$

\begin{tabular}{lc}
\hline \multicolumn{1}{c}{ Sample } & $T_{\mathrm{c}},{ }^{\circ} \mathrm{C}$ \\
\hline Solution & 70 \\
Wet crystal & 70 \\
Crystal dried at low temp & 105 \\
Heat treated crystal & 154 \\
Moisture regained crystal & 137 \\
Dry crystal & 195 \\
\hline
\end{tabular}

a Heating rate, $5^{\circ} \mathrm{C} / \mathrm{min}$; sample weight, $5 \mathrm{mg}$.

the crystal, and due to the smaller sample weight, the less water content per cell space. The remarkable dependence of $T_{\mathrm{c}}$ on the water content is shown in Table III.

Table III shows these sharp endothermal peak temperatures $\left(T_{\mathrm{c}}\right)$ of various samples observed closed microDTA. In this table, solution means the mother liquid used for the crystallization and wet crystal is the crystalline sample containing much water. Crystal dried at low temp means the one dried in air at $4{ }^{\circ} \mathrm{C}$ and $70-\%$ RH. A crystalline sample which was placed in the closed cell after air drying at $110^{\circ} \mathrm{C}$ for about $5 \mathrm{~min}$ was used as heat treated crystal. Moisture regained crystal means the sample kept in $18^{\circ} \mathrm{C}$ and $60-\% \mathrm{RH}$ for $1 \mathrm{hr}$ after the heat treatment. Dry crystal was the sample dried according to the conditions described in materials. As is evident from Table III, the endothermal peak shifted to a higher temperature with progressive drying of the crystals, asymptotically approaching a temperature of $202^{\circ} \mathrm{C}$ at which a perfectly dry crystal melted.

By optical observation of the crystalline shape and DTA measurement in an open cell, the endothermal peak at about $200^{\circ} \mathrm{C}\left(T_{\mathrm{b}}\right)$ is considered to be the melting point of the perfectly dry crystal. On the other hand, the endothermal peak temperature, $T_{\mathrm{c}}$, is considered to be 


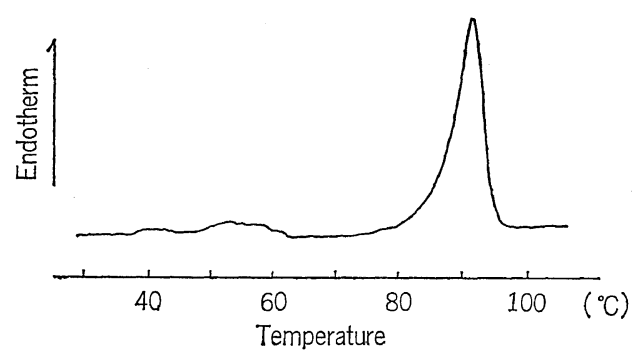

Figure 9. DSC curve of crystalline lysozyme having to endothermal peaks: Rate, $2.5^{\circ} \mathrm{C} / \mathrm{min}$; sample weight, $5 \mathrm{mg}$.

the melting point of the samples in a closed cell, where melting of the crystals occurs below $200^{\circ} \mathrm{C}$ due to the plasticizing effect of contained water. This identification of the peak $\left(T_{\mathrm{c}}\right)$ is verified by the fact that the samples which undergo endothermal reaction at $T_{\mathrm{c}}$ in a closed cell have no endothermal peak at about $200^{\circ} \mathrm{C}$ in an open cell.

These endothermal peak temperatures, $T_{\mathrm{c}}$, were independent of the hysteresis of water absorption and shifted continuously from about 70 to $200^{\circ} \mathrm{C}$ as the water content decreased as mentioned above. This relation is shown in Figure 9.

The appearance and the shift of $T_{\mathrm{c}}$ can be related to the opening-up of the molecule and the melting of the crystal, respectively, and this problem will be discussed in the following chapter.

An attempt was also made to clarify the thermal behavior of the lysozyme crystals in the temperature range from 20 to $50^{\circ} \mathrm{C}$. Using microDTA and DSC a small broad endothermal peak was observed in these regions. The shape and the position of this peak changed according to the water content of the sample. As an example an endothermal curve in DSC is shown in Figure 10 where two broad endothermal peaks seem to exist in the temperature region below the melting point $\left(90^{\circ} \mathrm{C}\right)$.

\section{DISCUSSION}

First, we shall discuss the motional narrowing of the broad component in broad line PMR spectra and the endothermal peak in DTA curves observed at a temperature of about $70^{\circ} \mathrm{C}$ in the wet crystalline lysozyme. In high-resolution PMR spectra of the lysozyme solution, an abrupt change of spectra in an upfield resonance region, which is due to the protons in varine, leucine, isoleucine methyl regions, has been observed above $71^{\circ} \mathrm{C}$. It has been clarified by optical rotatory dispersion study that this striking change is caused by the transition from a folded to an unfolded structure of the lysozyme

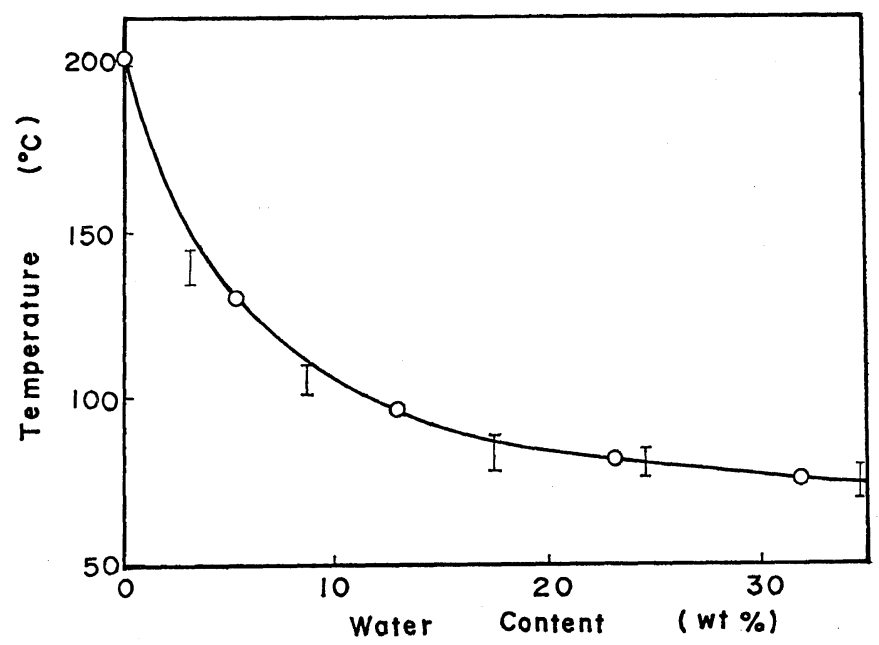

Figure 10. Endothermal peak and PMR-line narrowing temperature vs. water content in the crystals: I, the narrowing temperature of the broad component; $O$, endothermal peak temperature: Rate, $5^{\circ} \mathrm{C} / \mathrm{min}$; sample weight, $5 \mathrm{mg}$. 
molecule. ${ }^{3}$ In our experiment on the crystalline lysozyme containing a lot of water, the line narrowing of the broad component and the endothermal peaks $\left(T_{\mathrm{c}}\right)$ were also observed at about $70^{\circ} \mathrm{C}$. In addition to these results, our experimental results showed that the area of the endothermal peak $\left(T_{\mathrm{c}}\right)$ in the DTA curve of crystalline lysozyme was almost identical to that of the solution containing the same weight of lysozyme. This means that the transition enthalpy is of the same order in both cases. It will therefore be reasonable to assume that a similar conformational change as observed in solution occurs in the crystalline lysozyme containing much water. The fact that this change was observed at almost the same temperature in both cases shows that intermolecular interaction in the wet crystals does not influence the unfolding of the molecule.

As is well known, the enthalpy change accompanied by a helix-coil transition of polypeptides is generally very small. ${ }^{21,22}$ From the fact that endothermal peak observed in lysozyme is fairly large, it is considered that this enthalpy change is not brought about just by an unfolding of the helical regions. Other changes of state that occur simultaneously with the unfolding of the helix and generate large enthalpy changes must also be considered. Such a change as proposed by Sternlicht and Wilson ${ }^{3}$ based on high-resolution PMR studies of lysozyme solution is the opening-up of the molecule at about $75^{\circ} \mathrm{C}$. The contact of water with hydrophobic parts in the molecule perhaps gives rise to large changes in enthalpy.

Let us consider the dependence of $T_{\mathrm{c}}$ on the amount of the absorbed water to be a phenomenon analogous to melting point depression. Flory showed that the melting temperature of a polymer-diluent system, $T_{\mathrm{m}}$, is expressed as follows. ${ }^{23}$

$$
1 / T_{\mathrm{m}}-1 / T_{\mathrm{m}}{ }^{\circ}=\left(R / \Delta H_{\mathrm{u}}\right)\left(V_{\mathrm{u}} / V_{1}\right)\left(v_{1}-B V_{1} v_{1}^{2} / R T_{\mathrm{m}}\right)
$$

where $T_{\mathrm{m}}{ }^{\circ}$ is the melting point of the pure polymer, $H_{\mathrm{u}}$ is the heat of fusion per repeating unit, $V_{1}, V_{\mathrm{u}}$ are the molar volumes of the solvent and of the structural unit, respectively, $v_{1}$ is the volume fraction of the solvent, and $B$ represents the interaction-energy-density characteristic of the solvent-solute pair.

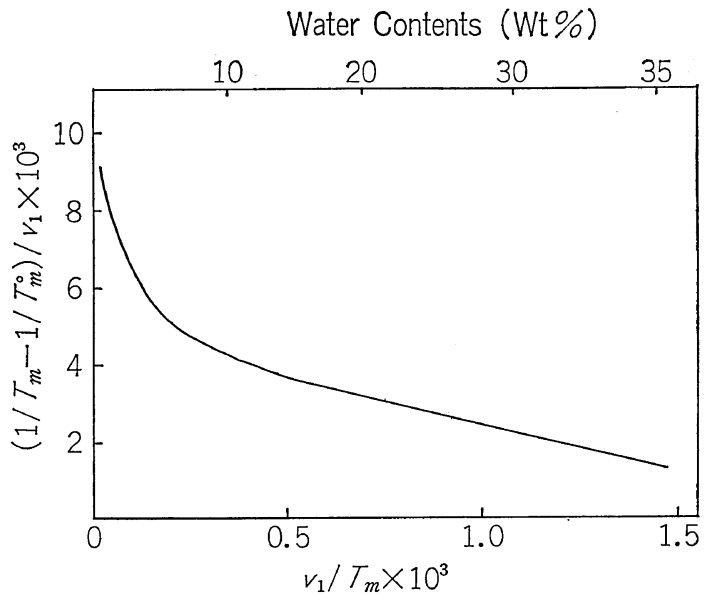

Figure 11. $\left(1 / T_{\mathrm{m}}-1 / T_{\mathrm{m}}{ }^{\circ}\right) / v_{1}$ plotted against $v_{1} / T_{\mathrm{m}}$ for lysozyme crystal containing water.

This equation requires that the plot of $\left(1 / T_{\mathrm{m}}\right.$ $\left.-1 / T_{\mathrm{m}}{ }^{\circ}\right) / v_{1}$ vs. $v_{1} / T_{\mathrm{m}}$ must be linear. Experimental data supporting this relationship have been obtained with many linear polymers including fibrous proteins such as collagen and gelatine. ${ }^{24,25}$ However, there is some doubt about this theory being applicable for globular proteins as well. To see whether or not this relationship holds in crystalline lysozyme, Figure 10 was replotted in Figure 11. Here, weight percent of the solvent has been converted to the volume fraction of the solvent by taking dry density of lysozyme as $1.3 \mathrm{~g} / \mathrm{cm}^{3}$.

In a region where $v_{1} / T_{\mathrm{m}}$ is larger than $0.5 \times$ $10^{-3} \mathrm{~K}^{-1}$ or weight percent of water exceeds $15 \%$, a linear relationship holds, showing that water is a simple diluent. Thus in this region the shift of the transition temperature may be explained as a melting point depression as expressed by Flory's theory. However, when weight percent of water decreases below $15 \%$, the tangential slope of the curve increases, showing that water is no longer a simple diluent. It may be considered that the interaction energy between water and lysozyme molecules is larger in the region where the water content is below $15 \mathrm{wt} \%$. This agrees with the consideration of Bull and Breese, ${ }^{26}$ who showed that differential enthalpy of egg albumin increases with decreasing water content.

Our preliminary data from X-ray analysis showed that the lattice distances of the crystal 
diminished with decreasing water content. Thus, during the process of dehydration, the intermolecular interactions of the crystal increased and the lysozyme crystal becomes very stable against heat. It is to be noted that this process is perfectly reversible with regard to the water contents.

It is generally known that the enzymatic activity of lysozyme rapidly decreases if the temperature exceeds $70^{\circ} \mathrm{C}$ in solution. This activity loss may be caused by a drastic conformational change in the molecule. In the crystalline state, the mobility of the lysozyme molecule is restricted by intermolecular interactions in the relatively dry state, so the conformational change does not occur so long as the crystals do not melt. The melting point of the crystals is high enough to produce an opening-up of the lysozyme molecule. The opening-up of the lysozyme molecule therefore, occurs simultaneously with the melting of the crystals. The melting point of the crystals with lower water contents is higher than $70^{\circ} \mathrm{C}$, so the enzymatic activity would be preserved even by the heat treatment above $70^{\circ} \mathrm{C}$, so long as the crystals do not melt. Our preliminary experimental results on the enzymatic activity of heat treated lysozyme support the above expectation. As a summary of the preceding discussion, it may be reasonable to conclude that the melting of the crystal induces the opening-up of the molecule, and as a result of the opening-up, the endotherm in DTA or the line narrowing in PMR are observed.

Next, we shall discuss motional properties observed in the temperature region between 20 and $50^{\circ} \mathrm{C}$. Motional narrowing in the narrow component of the broad-line PMR was observed in these temperature regions. The percentage of protons contributing to the narrow component was approximately $5 \%$ of the total protons not replaced by deuterium (about 700 protons per lysozyme molecule), and when the temperature was changed from room temperature to $160^{\circ} \mathrm{C}$, the change in this value was negligible (see Figure 4). Accordingly, it is reasonable to assume that the exchange of protons between the broad and the narrow components at these temperatures does not occur in the crystalline lysozyme. There are two possibilities by which proton groups can contribute to this narrow component. One is the contribution from the proton group not replaced by deuterium and placing in the higher movable parts in the lysozyme molecules and the other is that from the proton group of water molecules contained as contamination. To understand which proton groups are more essential for the appearance of the narrow component, we are now carrying out supplementary experiments using high-resolution PMR. A small endothermal peak in DTA was also observed in these temperature regions corresponding to the narrowing in PMR. Privalov, et al. ${ }^{27}$ have studied thermal conformational transformation of globular protein and shown the existence of a predenaturational stage where the partial heat capacity of the protein changes. In our recent high-resolution PMR $(60 \mathrm{MHz})$ studies on wet crystalline lysozyme, only one proton signal which came mainly from the water proton and has a bandwidth of about $10 \mathrm{~Hz}$ was observed in the whole sweep range $(1080 \mathrm{~Hz})$, and the width of the signal showed marked narrowing in the temperature range from 20 to $50^{\circ} \mathrm{C}^{28}$ It may be expected that some molecular motion corresponding to the narrowing of the narrow component of the broad-line PMR spectrum is related to the maximum enzymatic reaction rate observed in these temperature regions. The problem of this molecular motion, especially of its relations with the optimum condition of the enzymatic reaction will be discussed in the following paper.

Acknowledgment. The authors express their sincere thanks to Professor R. Chûjô of Tokyo Institute of Technology for his illuminating discussion and Professor S. Hayashi of Gunma University for valuable comments. Thanks are also due to Mr. T. Kuroda of Katata Research Institute of Toyobo Co., Ltd. for the measurement of a part of the broad-line PMR. This work has been supported in part by the Grantin-Aid from the Ministry of Education.

\section{REFERENCES}

1. M. Mandel, Proc. Nat. Acad. Sci. U.S., 52, 736 (1964).

2. C. C. McDonald and W. D. Phillips, J. Amer. 
Chem. Soc., 89, 6332 (1967).

3. H. Sternlicht and D. Wilson, Biochem., 6, 2881 (1967).

4. K. Hamaguchi and K. Imahori, J. Biochem., 55, 388 (1964).

5. K. Hamaguchi, ibid., 56, 441 (1964).

6. S. B. Dubin, N. A. Clark, and G. B. Benedek, J. Chem. Phys., 54, 5158 (1971).

7. C. C. F. Blake, D. F. Koenig, G. A. Mair, A. C. T. North, D.C. Pillips, and V. R. Sarma, Nature, 206, 757 (1965).

8. L. N. Johnson and D.C. Phillips, ibid., 206, 757 (1965).

9. D. C. Phillips, Scientific American, 251, 78 (1966).

10. C. C. F. Blake, L. N. Johnson, G. A. Mair, A.C. T. North, D.C. Phillips, and V.R. Sarma, Proc. Roy. Soc., 167, 378 (1967).

11. K. Hamaguchi, K. Rokkaku, M. Hunatu, and K. Hayashi, J. Biochem., 48, 351 (1960).

12. K. Hayashi, T. Imoto, and M. Hunatu, ibid., 54, 381 (1963).

13. J. A. Rupley and V. Gates, Proc. Nat. Acad. Sci. U.S., 57, 496 (1967).

14. D. Chipman, V. Grisaro, and N. Sharon, $J$. Biol. Chem., 242, 4388 (1967).
15. M. A. Ruftery, F. W. Dahlquist, S. I. Chan, and S. M. Parsons, ibid., 243, 4175 (1968).

16. D. M. Blow and T. A. Steitz, Ann. Rev. Biochem., 39, 63 (1970).

17. R. Chûjô, J. Phys. Soc. Japan, 18, 124 (1963).

18. S. Iwayanagi and Y. Sugiura, Rep. Progr. Polym. Phys. Japan, 8, 529 (1970).

19. D. Puett, Biopolymers, 5, 327 (1967).

20. F. Happy and M. Watson, ibid., 5, 1029 (1967).

21. T. Ackermann and H. Rueterjons, Z. Physik. Chem. (Frankfurt), 41, 116 (1964).

22. F. E. Karasz, J. M. O'Reilly, and H. E. Bair, Nature, 202, 693 (1964).

23. P. J. Flory, "Principle of Polymer Chemistry," Cornell University Press, Ithaca, N.Y., 1953, Chapter 8.

24. P. J. Flory and R. R. Garett, J. Amer. Chem. Soc., 80, 4836 (1958).

25. D. E. Roverts and L. Mandlkern, ibid., 77, 781 (1955).

26. H. B. Bull and K. Breese, Arch. Biochem. Biophys., 128, 488 (1968).

27. P. L. Privalov, N. N. Khechinashvili, and B.P. Atanasov, Biopolymers, 10, 1865 (1971).

28. T. Takizawa and Y. Miyoshi, Rep. Progr. Polym. Phys. Japan, 14, 595 (1971). 